\title{
PENGARUH KEPRIBADIAN BIG FIVE DAN \\ COPING STRESS TERHADAP KECERDASAN EMOSI PADA MAHASISWA KEDOKTERAN DI JAKARTA
}

\author{
Ridha Hanifah Margolang \\ ridhahanifah94@gmail.com \\ mailto:afifah.fauziyyah.af@gmail.com
}

Anggota HIMPSI Provinsi Banten

\author{
Risatianti Kolopaking \\ risakolopaking@gmail.com \\ Fakultas Psikologi UIN Syarif \\ Hidayatullah Jakarta
}

\begin{abstract}
This study was conducted to know the significance influence of the big five personality (extraversion, agreeableness, conscientiousness, openness, neuroticism) and coping stress (confrontive coping, distancing, self-control, social support accepting responsibility, escape avoidance, planful problem solving, positive reappraisal) towards emotional intelligence. Participants in this study are medical students of State and Private Universities in Jakarta who are undergoing pra-clinic / Co-Assistant period from the 8th to 11th semester and taken by snowball sampling technique. The CFA technique (Confirmatory Factor Analysis) was used to test the validity of the measuring instrument and multiple regression analysis was used to test the research hypothesis. The results showed that the big five personality variable and coping stress had a significant influence towards emotional intelligence. A large proportion of the variance of emotional intelligence that is explained by all independent variables of $63.5 \%$, while the remaining $36.5 \%$ are influenced by other variables outside this research. There are six variables that have significant effect on emotional intelligence which is agreeableness, openness, self control, social support, planful problem solving, positive reappraisal. Meanwhile, the variables of extraversion, consciencetiousness, neurotiscm, confrontive coping, distancing, accepting responsibility, escape avoidance, has no significant effect on emotional intelligence. Researcher suggest that all medical faculty creates emotional intelligence as an additional course so they can understand and practice how to control their emotions properly.
\end{abstract}

Keywords: big five personality, coping stress, emotional intelligence

\begin{abstract}
Abstrak
Penelitian ini dilakukan untuk mengetahui signifikansi pengaruh kepribadian big five (extraversion, agreeableness, conscientiousness, openness, neuroticism) dan coping stress (confrontive coping, distancing, self control, seeking social support, accepting responsibility, escape avoidance, planful problem solving, positive reappraisal) terhadap kecerdasan emosi. Partisipan dalam penelitian ini adalah mahasiswa kedokteran Universitas Negeri dan Swasta di Jakarta yang sedang menjalani masa praklinik/masa koas mulai dari semester 8 sampai semester 11 dan diambil dengan teknik snowball sampling. Teknik CFA (Confirmatory Factor Analysis) digunakan untuk menguji validitas alat ukur dan multiple regression analysis digunakan untuk menguji hipotesis penelitian. Hasil penelitian menunjukkan bahwa variabel kepribadian big five dan coping stress berpengaruh signifikan terhadap emotional intelligence. Besar proporsi varians dari kecerdasan emosi yang dijelaskan oleh seluruh variabel independen sebesar $63.5 \%$, sedangkan sisanya yaitu $36.5 \%$ dipengaruhi oleh variabel lain di luar penelitian ini. Terdapat enam variabel yang berpengaruh signifikan terhadap emotional intelligence yaitu agreeableness, openness, self control, seeking social support, planful problem solving, positive reappraisal. Sedangkan variabel extraversion, consciencetiousness, neurotiscm, confrontive coping, distancing, accepting responsibility, escape avoidance, tidak berpengaruh signifikan terhadap kecerdasan emosi. Peneliti menyarankan untuk semua fakultas kedokteran menjadikan kecerdasan emosi sebagai bahan tambahan pelajaran mata kuliah agar mereka dapat memahami dan melatih bagaimana mengontrol emosinya dengan baik.
\end{abstract}

Kata kunci: kepribadian big five, coping stress, kecerdasan emosi

Diterima: 07 Juli 2017 Direvisi: 17 Agustus $2017 \quad$ Disetujui: 27 September 2017 


\section{PENDAHULUAN}

Mahasiswa kedokteran yang telah menyelesaikan masa pendidikan kedokteran, harus menjalani tahap profesi kedokteran atau praklinik. Pada saat mahasiswa kedokteran menjalani masa kliniknya, mahasiswa kedokteran disebut sebagai mahasiswa ko-asisten. Dalam penelitian ini peneliti selanjutnya akan menyebut mahasiswa kedokteran yang sedang menjalani masa klinik sebagai mahasiswa ko-asistensi.

Mahasiswa ko-asisten diharapkan dapat menyelesaikan stasenya tepat pada waktunya walaupun mereka mempunyai tuntutan untuk belajar lebih lama, memiliki empati tinggi terhadap pasien, tidak memilih-milih pasien, dapat membangun komunikasi yang baik dengan pasien, mempunyai sikap jujur, tanggung jawab, dan sabar dalam menghadapi pasien. Namun pada kenyataannya mahasiswa ko-asisten ada yang lama dalam menyelesaikan masa stasenya, mahasiswa ko-asisten juga kerap kali merasakan ketidakmampuan mereka dalam menjalani tuntutan mereka sebagai dokter profesi, kurang memahami perasaan pasien, tidak dapat memotivasi diri ketika mahasiswa koasisten merasa tertekan dengan segala rangkaian tuntutan dan ketika menghadapi dokter konsulen yang sangat tegas, mahasiswa ko-asisten juga kurang mempunyai komunikasi yang hangat dengan pasien sehingga mahasiswa koasisten kurang mendapatkan informasi yang didapat dan membuat pasien kesal karena mahasiswa ko-asisten menanyakan kembali apa yang dirasakan pasien.

Oleh karena itu dalam kondisi ini mahasiswa ko-asisten diperlukan untuk mengelola, mengenali emosi orang lain, dan memotivasi dirinya ketika mereka menghadapi berbagai tekanan-tekanan yang membutuhkan kemampuan dalam mengendalikan emosi. Dimana hal tersebut merupakan bagian dari kecerdasan emosi. Kecerdasan emosi adalah kemampuan individu untuk mengetahui emosi seseorang, mengelola emosi, memotivasi diri, mengenali emosi orang lain, dan mengelola hubungan dengan orang lain (Goleman dalam Lunenburg (2011)). Melalui kecerdasan emosi seseorang dapat mengontrol emosi baik di dalam diri sendiri ataupun orang lain, terutama dalam dunia medis yang merupakan lingkup yang banyak tantangan dalam segi psikis yaitu perasaan dan emosi. Dalam penelitian Humpel dan Caputi dalam Por, Barriball, Fitzpatrick, dan Roberts (2011) menyatakan bahwa keperawatan adalah pekerjaan yang penuh tekanan dan penempatan klinis yang mengekspos siswa pada tahap awal dalam studi mereka terhadap kenyataan bahwa bekerja sebagai profesional kesehatan. Mahasiswa perawat perlu mengembangkan kemampuan untuk mengendalikan emosinya dan menyalurkan suasana hati mereka secara konstruktif karena ketidakmampuan mengatur diri sendiri dapat menyebabkan peningkatan stres dan kecemasan.

Libbrech et al (2013) mengatakan bahwa kecerdasan emosi harus dimiliki oleh seorang individu sehingga mampu mengembangkan dukungan sosial yang lebih baik dan mengembangkan hubungan interpersonal yang lebih baik. Hal ini menjadi penting untuk dimiliki oleh profesi kedokteran khususnya mahasiswa koasisten, karena ketika mereka melakukan sebuah treatment mereka harus menjalin hubungan yang baik dan nyaman agar pasien menjadi lebih terbuka dan percaya akan proses pengobatan yang akan dilakukan. Penelitian lain yang 
dilakukan oleh Chew, Zain, dan Hassan (2013), juga menyatakan hal sama yaitu kecerdasan emosi adalah salah satu domain psiko-afektif dalam pendidikan kedokteran, berkaitan dengan kinerja klinis dan prestasi akademik yang lebih tinggi dan dalam praktek klinis, telah berhubungan dengan peningkatan empati dalam konsultasi medis, hubungan dokter-pasien, kinerja klinis dan kepuasan pasien.

Kecerdasan emosi mempunyai peran penting dalam dunia kedokteran tidak hanya berdampak pada diri sendiri yang dapat mengatur suasana emosi pada situasi yang baik akan tetapi kepada pasien-pasien yang dihadapi mahasiswa koasisten tersebut. Dengan munculnya kecerdasan emosi ini membangun komunikasi antara pasien dan mahasiswa ko-asisten sehingga munculnya kepercayaan dalam pemeriksaan dan pengobatan serta kepuasaan pasien terhadap dokter. Selain itu dengan adanya kecerdasan emosi pada mahasiswa koasisten tentunya dapat membuat kinerja akademik mahasiswa ko-asisten menjadi baik tidak hanya secara akademis saja melainkan kinerjanya dalam merawat pasien. Seperti penelitian Todres, Tsimtsiou, Stephenson, dan Jones (2010), mengatakan bahwa kecerdasan emosi memiliki keterkaitan dengan kinerja akademik mahasiswa ko-asisten dalam pendidikan kedokteran. Serta memiliki hubungan dengan komunikasi klinis akan kualitas perawatan pasien.Selain itu kecerdasan emosi juga berperan dalam kerjasama antara pasien dan dokter yang merupakan sebagai faktor keberhasilan dalam pemeriksaan klinis. Seorang dokter perlu untuk meredakan kecemasan pasien terlebih dalam proses pengobatan akut, Libbrech, Lievens, Carrete, dan Cote (2013).

Pada hakikatnya kecerdasan emosi sudah ada sejak manusia dilahirkan dan berkembang selama masa pertumbuhan dan perkembangan manusia itu sendiri. Dalam proses perkembangan banyak suatu peristiwa yang terjadi dan secara tidak langsung mengasah pendewasaan emosi seseorang. Pada saat proses pendewasaan seseorang tentu ada peran kepribadian dalam membentuk pendewasaan emosi. Dalam Sindhuja, Shrivasta, Gambhir, dan Chaturvedula (2013) mengatakan bahwa kecerdasan emosi merupakan bagian dari kepribadian dan kepribadian manusia yang menyediakan konteks kecerdasan emosi beroperasi. Kepribadian didefinisikan sebagai apa yang memungkinkan prediksi tentang apa yang akan dilakukan seseorang dalam situasi tertentu, sifat kepribadian adalah mekanisme di dalam diri seseorang membentuk bagaimana seseorang itu beraksi terhadap tiap-tiap kejadian. Kecerdasan Emosi dipengaruhi oleh kepribadian.

Kepribadian memungkinkan untuk memprediksi apa yang akan seseorang lakukan dalam situasi tertentu. Ciri-ciri kepribadian dalam diri individu membentuk bagaimana seseorang bereaksi terhadap peristiwa yang dialaminya (Sindhuja et al, 2013). Hal ini berpengaruh bagaimana seseorang menggunakan dan merasakan emosi melalui tindakan perilakunya dalam menyikapi suatu permasalahan yang dialami. Kepribadian merupakan topeng yang dipakai untuk menampilkan diri pada lingkungan sekitarnya. Kepribadian meliputi semua sifat atau karakteristik yang relatif permanen yang menyababkan konsistensinya suatu perilaku manusia (Jess \& Gregory, 2010).

Dari beberapa tipe kepribadian salah satunya adalah kepribadian big five. Leiss Goldberg yang mempelopori istilah Big Five pada tahun 1981 adalah untuk 
analisis faktor dari sifat kepribadian, akan tetapi selanjutnya dikembangkan oleh McCrae Costa. (Jess \& Gregory, 2010). Kepribadian big five digunakan untuk mengidentifikasi kepribadian seseorang kedalam lima dimensi yaitu extraversion, agreeableness, conscientiousness, openness, neuroticism. Seperti dalam penelitian Atta, Ather, dan Bano (2013), menyatakan bahwa big five mempunyai pengaruh terhadap kecerdasan emosi yaitu pengaruh positif terhadap extraversion, agreeableness, openness, conscientiousness dan mempunyai pengaruh yang negatif terhadap neuroticism.

Selain itu kecerdasan emosi dipengaruhi faktor lainnya yaitu coping stress dalam mengelola kemampuan kecerdasan emosi. Coping stress ini adalah perubahan kognitif dan perilaku untuk mengelola tuntutan eksternal dan atau internal secara spesifik yang dinilai sebagai melebihi dari kemampuan diri kita (Lazarus \& Folkman, 1984). Seseorang yang dapat mampu menggunakan dengan baik kecerdasan emosi tentunya mudah menciptakan coping yang baik dalam menangani pasien ketika terjadinya kesenjangan teori yang dipelajari itu tidak seseuai atau bahkan ketidakpercayaan diri mahasiswa tersebut. Serta dapat mengontrol emosinya ketika menghadapi berbagai tekanan yang membuat mereka stres.

Dalam penelitian di Iran pada tahun 2010 menunjukkan bahwa coping stress mempengaruhi kecerdasan emosi melalui manajemen dan regulasi emosi, pemanfaatan dan fasilitasi emosi, dan penilaian emosi (Noorbakhsh, Besharat, dan Zarei, 2010). Menurut Lazarus \& Folkman dalam Shelley (2009) mengatakan bahwa coping stress dibagi menjadi dua tipe upaya yaitu pertama, usaha pemecahan masalah berupa melakukan suatu upaya untuk mengubah situasi stres. Kedua, usaha dalam mengatur emosi yaitu usaha yang menata emosi terhadap peristiwa yang menyebabkan stress.

\section{KAJIAN TEORI}

\section{Kecerdasan Emosi}

\section{Definisi kecerdasan emosi}

Profesor Howard Gardner dalam Yahaya, Bachok, Yahaya, Bon, dan Ismail (2011), pada awalnya mengembangkan studi dalam kecerdasan manusia. Gardner menemukan tujuh kecerdasan yang dua diantaranya dikenal sebagai intrapersonal intelligence dan interpersonal intelligence terkait dengan kecerdasan emosi. Intrapersonal intelligence adalah kemampuan seseorang untuk mengendalikan diri melalui pengetahuan dan pemhaman perasaan, keinginan, kebutuhan dan tujuan pribadi. Sedangkan interpersonal intelligence adalah kemampuan dan kepekaan emosional dengan keadaan psikologis orang lain.

Kemampuan ini dapat membantu seseorang untuk memilih respon yang memadai, untuk merasakan empati dan berkomunikasi baik dengan orang lain. Jika seseorang yang memiliki kedua kecerdasan ini akan membentuk kecerdasan emosi yang tinggi. Menurut Mayer dan Salovey (1990), kecerdasan emosi adalah kemampuan untuk memantau sendiri dan orang lain akan perasaan dan emosi seseorang, untuk membedakan antara perasaan dan emosi serta menggunakan informasi ini untuk membimbing pikiran dan tindakan seseorang. 
Pengertian mengenai kecerdasan emosi kemudian berkembang menjadi kecerdasan emosi yang melibatkan kemampuan untuk memahami secara akurat, menilai, dan mengekspresikan emosi, kemampuan untuk mengakses atau menghasilkan perasaan ketika mereka memfasilitasi pemikiran, kemampuan untuk memahami emosi dan pengetahuan emosional, dan kemampuan untuk mengatur emosi, untuk mempromosikan emosional dan pertumbuhan intelektual (Salovey \& Mayers, 1997).

Kecerdasan emosi adalah kemampuan individu yang dapat mengidentifikasi perasaan mereka, perasaan orang lain, mengatur perasaan, dan menggunakan informasi yang diberikan oleh perasaan mereka untuk memotivasi perilaku adaptif (Salovey Stroud, Woolery, Epel, 2002). Goleman dalam Lunenburg (2011), mengatakan bahwa kecerdasan emosi adalah kemampuan individu untuk mengetahui emosi seseorang, mengelola emosi, memotivasi diri, mengenali emosi orang lain, dan mengelola hubungan dengan orang lain. Berdasarkan pengertian yang dijelaskan sebelumnya, dalam penelitian ini peneliti menggunakan pengertian kecerdasan emosi dari Goleman dalam Lunenburg (2011) yaitu kemampuan individu untuk mengetahui emosi seseorang, mengelola emosi, memotivasi diri, mengenali emosi orang lain, dan mengelola hubungan dengan orang lain.

\section{Dimensi variabel kecerdasan emosi}

Menurut Goleman (1998), mengatakan bahwa dimensi kecerdasan emosional yaitu:

(1) Self-awareness adalah kemampuan untuk mengenali apa yang dirasakan, untuk memahami tanggapan emosional, mengenali bagaimana emosi dapat mempengaruhi perilaku dan kinerja. Sedangkan dimensi lain menurut Mayers dan Salovey dalam Brackett, River, dan Salovey (2011), adalah understanding emotion yaitu kemampuan mengenali persamaan dan perbedaan antara label emosi dan emosi diri sendiri, menafsirkan makna dan asal emosi (misalnya, kesedihan dapat hasil dari kerugian) dan memahami perasaan kompleks seperti suasana hati (merasa baik, tertarik, dan bosan), atau campuran dari perasaan (penghinaan sebagai kombinasi dari jijik dan marah).

(2) Managing emotions kemampuan untuk tetap fokus dan berpikir jernih bahkan ketika mengalami emosi yang kuat. Mayers dan Salovey dalam Brackett et al (2011), juga menjelaskan dimensi lain yaitu using emotion yaitu kemampuan yang mengacu pada memanfaatkan emosi untuk memfasilitasi kegiatan kognitif seperti penalaran, pemecahan masalah, dan komunikasi interpersonal, serta keterampilan yang melibatkan emosi untuk menilai, proses emosi, dan menghasilkan suasana hati.

(3) Motivation adalah kemampuan untuk menggunakan emosi terdalam bertindak dan membimbing menuju tujuan, serta memungkinkan untuk mengambil inisiatif dan bertekun dalam menghadapi rintangan dan kemunduran. 
(4) Empathy adalah kemampuan untuk merasakan, memahami dan menanggapi apa yang orang lain rasakan.

(5) Social skills adalah kemampuan untuk mengelola emosi, menangani emosi, mampu mempengaruhi dan menginspirasi orang lain. Sedangkan menurut Mayers dan Salovey dalam Brackett et al (2011) adalah Managing emotion merupakan kemampuan memodifikasi respons emosional dalam diri sendiri dan orang lain, mengalami berbagai emosi saat membuat keputusan akan kelayakan dan kegunaan dari emosi dalam situasi tertentu.

\section{Kepribadian Big Five Theory}

Definisi kepribadian big five theory

Menurut Pervin (2004), kepribadian Big Five adalah penggambaran faktor-faktor dalam banyak golongan sifat tertentu. McCrae dan Costa dalam Feist dan Feist (2010), menyatakan bahwa kepribadian big five suatu usaha untuk mengidentifikasi sifat dasar kepribadian seseorang yang terungkap lewat analisis faktor sehingga dapat memprediksi dan menjelaskan perilaku seseorang. Kepribadian Big Five yang dikembangkan oleh McCrae dan Costa mengenai taksonomi sifat dari kepribadian yang seiring pertambahan usia cenderung mempertahankan struktur kepribadiannya.

Dimensi kepribadian big five

Adapun dimensi kepribadian big five menurut McCrae dan Costa (2003) yaitu:

(1) Extraversion seseorang dengan trait memiliki sifat yang selalu ingin sibuk, bertindak penuh semangat dan berbicara dengan cepat, energik, kuat memilih lingkungan yang dapat merangsang mereka dan sering mencari kegembiraan.

(2) greeableness seseorang yang memiliki trait yang perhatian tanpa pamrih untuk orang lain, murah hati, mudah percaya pada orang lain dan jarang mencurigai maksud tersembunyi, menunjukkan kesederhanaan.

(3) Consciencetiousness sifat trait ini teliti, rasional, tahu, umumnya menganggap diri mereka sebagai seseorang yang memiliki kompetensi tinggi, kesuksesan mereka dalam suatu organisasi membuat mereka efisien dalam bekerja, mengejar yang terbaik dalam segala hal, mempunyai kedipsilinan yang tinggi, membuat rencana terlebih dahulu dan berpikir dengan hati-hati sebelum bertindak.

(4) Neuroticism seseorang dengan trait ini cenderung menyerah pada godaan, kerentanan menunjukkan ketidakmampuan untuk mengatasi stress,dalam situasi sosial mereka cemas dan malu, frustrasi dalam berurusan dengan orang lain, membuat permusuhan atau hal-hal yang semakin rumit.

(5) Openness sifat trait ini mengacu pada imajinasi yang hidup dan kecenderungan untuk mengembangkan lamunan yang rumit (kreatif) dalam estetika itu terlihat dalam kepekaan terhadap seni dan kecantikan, mengalami perasaan mereka sendiri dengan kuat, dan mereka menghargai 
pengalaman tersebut, melihatnya sebagai sumber makna dalam kehidupan, berempati dengan orang lain dalam situasi lain.

\section{Coping stress}

\section{Definisi coping stress}

Coping menurut Lazarus dan Folkman (1984) adalah sebagai perubahan upaya kognitif dan perilaku untuk mengelola tuntutan eksternal dan atau internal yang spesifik yang dinilai sebagai memberatkan atau melebihi sumber daya seseorang (Lazarus \& Folkman (1984)). Menurut Lazarus dan Lazarus (1994) coping adalah upaya yang telah kita lakukan dan berpikir untuk mengelola stres dan emosi yang terkait dengan apakah upaya ini akan berhasil.

\section{Dimensi coping stress}

Pada coping stress Folkman dan Lazarus dalam Suldo, Shaunessy, dan Hadesty (2008), membagi menjadi dua jenis yaitu:

(1) Problem Focused Coping merupakan pemecahan masalah atau melakukan sesuatu untuk merubah sumber stress.

(2) Emotion Focused Coping merupakan kondisi mengurangi atau mengelola emosi distress yang berhubungan dengan situasi. Akan tetapi Folkman dan Lazarus tidak menjelaskan dimensi dari coping stress ke dalam jenis-jenis coping stress maka peneliti memasukkan dimensi tersebut ke dalam jenis-jenis coping stress yaitu:

(a) Problem focus coping:

(1) Confrontive coping adalah menjelaskan upaya agresif untuk mengubah situasi, menunjukkan tingkat permusuhan/kemarahan. (2) Distancing adalah menjelaskan tanggapan upaya kognitif untuk melepaskan diri dari permasalahan yang terjadi dan menciptakan pandangan positif. (3) Planful problem solving adalah upaya fokus terhadap permasalahan yang disengaja untuk mengubah suatu situasi dengan proses analisis dalam memecahkan masalah. (4) Escape avoidance adalah respon akan harapan terhadap situasi masalah apakah akan berakhir atau tidak dan respon akan usaha dari perilaku melarikan diri atau menghadapi diri dari masalah. b) Emotion focused coping: (5) Self control adalah tanggapan seseorang untuk mengatur perasaan dan tindakan. (6) Seeking social support adalah menggambarkan upaya untuk mencari dukungan informasi seperti dukungan yang didapatkan melalui berbicara dengan orang lain agar mendapatkan saran, dukungan nyata seperti meminta bantuan kepada orang lain agar dapat melakukan sesuatu terhadap masalah yang dihadapi, dan dukungan emosional seperti dukungan untuk mendapatkan simpati dan pengertian dari orang lain. (7) Accepting responsibility adalah menjelaskan untuk mengakui peran diri sendiri ketika dalam masalah dan mencoba menempatkannya dengan baik. (8) Positive reappraisal adalah upaya untuk menciptakan makna positif dengan berfokus pada pendewasaan pribadi sekaligus religiusitas.

\section{HIPOTESIS PENELITIAN}

a. Hiposesis mayor

$\mathrm{H}_{0} \quad$ : Terdapat pengaruh yang signifikan antara kepribadian big five dan coping stress terhadap kecerdasan emosi pada mahasiswa kedokteran. 


\section{b. Hipotesis Minor}

$\mathrm{H}_{1}$ : Terdapat pengaruh yang signifikan trait extraversion terhadap kecerdasan emosi.

$\mathrm{H}_{2}$ : Terdapat pengaruh yang signifikan trait agreeableness terhadap kecerdasan emosi.

$\mathrm{H}_{3}$ : Terdapat pengaruh yang signifikan trait conscientiousness terhadap kecerdasan emosi.

$\mathrm{H}_{4} \quad$ : Terdapat pengaruh yang signifikan trait neuroticism terhadap kecerdasan emosi.

$\mathrm{H}_{5}$ : Terdapat pengaruh yang signifikan trait openness terhadap kecerdasan emosi.

$\mathrm{H}_{6}$ : Terdapat pengaruh yang signifikan confrontive coping terhadap kecerdasan emosi.

$\mathrm{H}_{7}$ : Terdapat pengaruh yang signifikan distancing terhadap kecerdasan emosi.

$\mathrm{H}_{8}$ : Terdapat pengaruh yang signifikan self control terhadap kecerdasan emosi.

$\mathrm{H}_{9} \quad$ :Terdapat pengaruh yang signifikan seeking social support terhadap kecerdasan emosi.

$\mathrm{H}_{10}$ : Terdapat pengaruh yang signifikan accepting responsibility terhadap kecerdasan emosi.

$\mathrm{H}_{11}$ : Terdapat pengaruh yang signifikan escape avoidance terhadap kecerdasan emosi.

$\mathrm{H}_{12}$ : Terdapat pengaruh yang signifikan planful problem solving terhadap kecerdasan emosi.

$\mathrm{H}_{13}$ : Terdapat pengaruh yang signifikan positive reappraisal terhadap kecerdasan emosi.

\section{METODE PENELITIAN}

\section{Populasi, sampel dan teknik pengambilan sampel}

Dalam penelitian ini peneliti menggunakan populasi mahasiswa kedokteran di Jakarta. Adapun karakteristik sampel yang digunakan oleh peneliti adalah mahasiswa kedokteran Universitas Negeri dan Swasta di Jakarta yang sedang menjalani ko-asisten semester 8-11. Jumlah mahasiswa didapatkan sebanyak 161 mahasiswa.

\section{Instrumen penelitian}

\section{Kecerdasan Emosi}

Kecerdasan emosi diukur dengan menggunakan Emotional Intelligence Questionnaire (EIQ) Daniel Goleman dan konsruksi alat ukur oleh peneliti. EIQ mempunyai 50 item yang mengukur dimensi dari kecerdasan emosi yaitu selfawareness, managing emotions, motivation oneself, empathy, social skills. Pengukuran menggunakan skala model Likert dengan empat rentang penilaian ( $1=$ sangat tidak sesuai, $2=$ tidak sesuai, $3=$ sesuai, dan $4=$ sangat sesuai).

\section{Kepribadian big five}

Kepribadian big five ini diukur dengan BFI (Big Five Inventory) terdiri dari 44 item. Akan tetapi peneliti menggunakan 29 item BFI yang telah diuji kembali nilai validitasnya. Kemudian peneliti mengambil nilai validitas yang tertinggi hingga menjadi 20 item untuk mengukur kepribadian big five dan skala ini merupakan skala yang diadaptasi oleh penulis, karena skala awal dikembangkan dengan Bahasa Inggris Pengukuran menggunakan skala model Likert dengan empat rentang penilaian $(1=$ sangat tidak sesuai, $2=$ tidak sesuai, $3=$ sesuai, dan $4=$ sangat sesuai). 


\section{Coping stress}

Coping stress ini diukur dengan The Ways of Coping Revised yang dikembangkan oleh Lazarus \& Folkman. Alat ukur ini terdiri dari 50 item dan terbagi menjadi 8 skala. Kemudian peneliti mengambil nilai validitas yang tertinggi pada item The Ways of Coping revised menjadi 32 item, serta peneliti mengadaptasi skala ini karena skala awalnya dikembangkan dengan Bahasa Inggris. Pengukuran menggunakan skala model Likert dengan empat rentang penilaian $(1=$ sangat tidak sesuai, 2 = tidak sesuai, 3 = sesuai, 4 = sangat sesuai).

\section{Teknik Analisis Data}

\section{Uji validitas}

Sebelum melakukan analisis data penelitian, dilakukan uji validitas alat ukur penelitian menggunakan CFA untuk mendapatkan butir-butir item yang layak untuk dianalisis regresi. Dari hasil uji validitas alat ukur penelitian didapatkan hasil sebagai berikut: (a) skala kecerdasan emosi, terdapat empat puluh sembilan item yang valid dan satu item yang di drop. (b) skala kepribadian big five, terdapat sembilan belas item yang valid dan satu item yang di drop. (c) skala coping stress, terdapat dua puluh sembilan item yang valid dan tiga item yang di drop.

\section{Teknik analisis}

Analisis data dalam penelitian ini menggunakan analisis regresi berganda.

\section{HASIL PENELITIAN}

\section{Tabel 1}

Deskripsi Nilai Statistik \& Kategorisasi Skor Variabel Penelitian dengan N=161

\begin{tabular}{lcccc}
\hline & \multicolumn{2}{c}{ Nilai Statistik } & \multicolumn{2}{c}{ Kategorisasi Skor } \\
Variabel & Min & Max & Tinggi n(\%) & Rendah n(\%) \\
\hline Kecerdasan Emosional & 30.07 & 75.97 & $63(41.17 \%)$ & $90(58.82 \%)$ \\
Extraversion & 22.99 & 68.34 & $90(58.82 \%)$ & $63(41.17 \%)$ \\
Agreeableness & 12.39 & 70.01 & $115(75.16 \%)$ & $38(24.83 \%)$ \\
Conscientiousness & 20.15 & 67.82 & $93(60.78 \%)$ & $60(39.21 \%)$ \\
Neurotiscm & 32.74 & 69.92 & $71(46.40 \%)$ & $82(53.59 \%)$ \\
Openess & 27.41 & 69.03 & $75(49.01 \%)$ & $78(50.98 \%)$ \\
Confrontive coping & 24.75 & 71.68 & $75(49.01 \%)$ & $78(50.98 \%)$ \\
Distancing & 30.63 & 68.69 & $75(49.01 \%)$ & $78(50.98 \%)$ \\
Self control & 30.40 & 65.51 & $64(41.83 \%)$ & $89(58.16 \%)$ \\
Seeking social support & 12.48 & 64.06 & $70(45.75 \%)$ & $83(54.24 \%)$ \\
Accepting responsibility & 30.23 & 65.21 & $65(42.48 \%)$ & $88(57.51 \%)$ \\
Escape avoidance & 24.46 & 61.39 & $68(44.44 \%)$ & $85(55.55 \%)$ \\
Planful problem solving & 30.59 & 67.94 & $52(33.98 \%)$ & $101(66.01 \%)$ \\
Positive reappraisal & 30.08 & 62.99 & $56(36.60 \%)$ & $97(63.39 \%)$ \\
\hline
\end{tabular}

Berdasarkan tabel diketahui deskripsi statistik pada setiap variabel. Kolom minimum dan maximum menjelaskan nilai minimum dan maximum pada setiap variabel. Dilihat dari kolom minimum diketahui bahwa variabel dimensi 
Agreeableness mempunyai nilai terendah dengan nilai 12.39. Sedangkan pada kolom maximum diketahui bahwa variabel kecerdasan emosi memiliki nilai tertinggi dengan nilai 75.97. Adapun nilai mean masing-masing variabel adalah 50. Untuk kategosisasi skor penelitian dapat diketahui presentase variabel kecerdasan emosi sebanyak 63 orang (41.17\%) pada kategori tinggi dan 90 orang (58.82\%) pada kategori rendah. Kemudian, untuk dimensi extraversion hasil persentase sebanyak 90 orang $(58.82 \%)$ pada kategori tinggi, 63 orang $(41.17 \%)$ pada kategori rendah. Dimensi agreeableness hasil persentase sebanyak 115 orang $(75.16 \%)$ pada kategori tinggi, sedangkan 38 orang $(24.83 \%)$ pada kategori rendah. Dimensi consciencetiousness hasil persentase sebanyak 93 orang $(60.78 \%)$ pada kategori tinggi dan 60 orang (39.21\%) pada kategori rendah. Dimensi neurotiscm hasil persentase sebanyak 71 orang (46.40\%) pada kategori tinggi dan 82 orang $(53.59 \%)$ pada kategori rendah. Dimensi openness hasil persentase sebanyak 75 orang (49.01\%) pada kategori tinggi dan 78 orang (50.98\%) pada kategori rendah.

Dimensi confrontive coping hasil persentase sebanyak 75 orang (49.01\%) pada kategori tinggi dan 78 orang (50.98\%) pada kategori rendah. Dimensi distancing hasil persentase sebanyak 75 orang (49.01\%) pada kategori tinggi dan 78 orang (50.98\%) pada kategori rendah. Kemudian dimensi self control hasil persentase 75 orang (49.01\%) pada kategori tinggi dan 78 orang (50.98\%) pada kategori rendah. Dimensi seeking social support hasil persentase sebanyak 70 orang (45.75\%) pada kategori tinggi dan 83 orang (54.24) pada kategori rendah. Dimensi accepting responsibility hasil persentase sebanyak 65 orang $(42.48 \%)$ pada kategori tinggi dan 88 orang $(57.51 \%)$ pada kategori rendah. Dimensi escape avoidance hasil persentase sebanyak 68 orang $(44.44 \%)$ dan 85 orang (55.55\%) pada kategori rendah. Dimensi planful problem solving hasil persentase sebanyak 52 orang $(33.98 \%)$ pada kategori tinggi dan 101 orang (66.01\%) pada kategori rendah. Dimensi positive reappraisal hasil persentase sebanyak 56 orang $(36.60 \%)$ pada kategori tinggi dan

97 orang $(63.39 \%)$ pada kategori rendah.

\section{Hasil Uji Hipotesis Penelitian}

Hasil pengujian hipotesis penelitian ini menjawab keseluruhan hipotesis yang telah peneliti uraikan. Penelitian ini menjawab hipotesis mayor peneliti, yakni:

$\mathrm{H}_{0}$ : Ada pengaruh yang signifikan pada variabel kepribadian big five (extraversion, agreeableness, conscientiousness, neurotiscm, openness) dan coping stress (confrontive coping, distancing, self control, seeking social support, accepting responsibility, escape avoidance, planful problem solving, positive reappraisal) terhadap kecerdasan emosi.

Tabel 3 menjawab keseluruhan hipotesis minor $\left(\mathrm{H}_{1}-\mathrm{H}_{13}\right)$ peneliti. Berdasarkan hasil yang didapat dalam pengujian hipotesis minor, terdapat enam variabel yang signifikan, yaitu agreeableness, openness, self control, seeking social support, planful problem solving, positive reappraisal. 
Tabel 2

Model Summary Analisis Regresi

$$
\begin{array}{cc}
\text { Std. } & \text { Change Statistics } \\
\text { Error of } &
\end{array}
$$

$\mathrm{R}$ Adjusted the R Square $\mathrm{F}$ Sig. $\mathrm{F}$ $\begin{array}{llllll}\text { Model R Square R Square Estimate Change Change df1 df2 Change } & \end{array}$

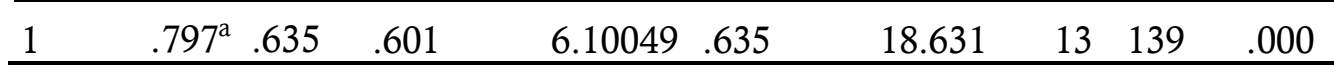

Dari tabel di atas dapat dilihat bahwa perolehan $\neg$ R-Square sebesar 0.635 atau $63.5 \%$ artinya proporsi varians dari kecerdasan emosi yang dijelaskan oleh variabel kepribadian big five yaitu extraversion, agreeableness, consciencetiousness, neurotiscm, openness, dan variabel coping stress yaitu confrontive coping, distancing, self control, seeking social support, accepting responsibility, escape avoidance, planful problem solving, positive reappraisal adalah sebesar $63.5 \%$ sedangkan $36.5 \%$ sisanya dipengaruhi oleh variabel lain di luar penelitian ini.

\section{Tabel 3}

Uji signifikansi regresi dari kepribadian big five dan coping stress terhadap kecerdasan emosi

\begin{tabular}{llccccc}
\multicolumn{8}{c}{ ANOVA $^{\mathrm{b}}$} \\
\hline \multirow{2}{*}{ Model } & \multicolumn{1}{c}{ Sum of } & & & & \\
\hline 1 & Squares & Df & Mean Square & F & Sig. \\
\hline & Regression & 9013.831 & 13 & 693.372 & 18.631 & $.000^{\mathrm{a}}$ \\
& Residual & 5173.025 & 139 & 37.216 & & \\
& Total & 14186.856 & 152 & & & \\
\hline
\end{tabular}

a. Predictors: (Constant), POSITIVE, NEUROTISCM, CONFRONTIVE, DISTANCING, OPENNESS, SEEKING, ESCAPE, SELF, CONSCIENTIOUSNESS, ACCEPTING, EKSTRAVERSI, AGREEABLENESS, PLANFUL

b. Dependent Variable: KECERDASAN

Berdasarkan uji F pada tabel 4, dapat dilihat bahwa nilai p (Sig.) pada kolom paling kanan adalah $\mathrm{p}=0.000$ dengan nilai $\mathrm{p}<0.05$. Maka hipotesis nihil yang menyatakan tidak ada pengaruh yang signifikan dari seluruh independen variabel terhadap kecerdasan emosi ditolak. Artinya, ada pengaruh yang signifikan dari kepribadian extraversi, agreeableness, consciencetiousness, neurotiscm, openness, confrontive coping, distancing, self control, seeking social support, accepting responsibility, escape avoidance, planful problem solving, positive reappraisal terhadap kecerdasan emosi pada mahasiswa ko-asisten di Jakarta.

Langkah selanjutnya, peneliti melihat koefisien regresi dari masing-masing IV, jika sig $<0.05$ maka koefisien regresi tersebut signifikan yang berarti variabel independen tersebut memiliki pengaruh yang signifikan terhadap kecerdasan emosi. Adapun besar koefisien regresi dari masing-masing variabel independen terhadap kecerdasan emosi dapat dilihat pada tabel 5. 


\section{Tabel 5}

Multiple regresi pengaruh kepribadian big five dan coping stress terhadap kecerdasan emosi Coefficients $^{\mathbf{a}}$

\begin{tabular}{|c|c|c|c|c|c|c|}
\hline \multirow{2}{*}{\multicolumn{2}{|c|}{ Model }} & \multicolumn{2}{|c|}{$\begin{array}{l}\text { Unstandardized } \\
\text { Coefficients }\end{array}$} & \multirow{2}{*}{$\begin{array}{c}\text { Standardiz } \\
\text { ed } \\
\text { Coefficient } \\
\text { s } \\
\text { Beta }\end{array}$} & \multirow[b]{2}{*}{$\mathbf{t}$} & \multirow[b]{2}{*}{ Sig. } \\
\hline & & B & Std. Error & & & \\
\hline \multirow[t]{14}{*}{1} & (Constant) & -15.755 & 6.903 & & -2.282 & .024 \\
\hline & EKSTRAVERSI & .051 & .069 & .048 & .742 & .459 \\
\hline & AGREEABLENESS & .145 & .070 & .136 & 2.078 & .040 \\
\hline & $\begin{array}{l}\text { CONSCIENTIOUSN } \\
\text { ESS }\end{array}$ & .054 & .075 & .049 & .712 & .478 \\
\hline & NEUROTISCM & -.080 & .059 & -.079 & -1.357 & .177 \\
\hline & OPENNESS & .170 & .072 & .150 & 2.352 & .020 \\
\hline & CONFRONTIVE & -.103 & .054 & -.106 & -1.918 & .057 \\
\hline & DISTANCING & .001 & .062 & .001 & .020 & .984 \\
\hline & SELF & .218 & .080 & .172 & 2.733 & .007 \\
\hline & SEEKING & .145 & .064 & .132 & 2.268 & .025 \\
\hline & ACCEPTING & .131 & .076 & .109 & 1.726 & .087 \\
\hline & ESCAPE & .118 & .064 & .109 & 1.838 & .068 \\
\hline & PLANFUL & .232 & .084 & .199 & 2.746 & .007 \\
\hline & POSITIVE & .234 & .078 & .203 & 2.998 & .003 \\
\hline & endent Variable: KECI & ASAN & & & & \\
\hline
\end{tabular}

\section{Proporsi varian}

Setelah melakukan uji regresi secara keseluruhan, peneliti ingin mengetahui sumbangan proporsi varians dari masing-masing independent variable terhadap kecerdasan emosi. Maka dari itu, peneliti melakukan analisis regresi berganda dengan cara menambahkan satu independent variable setiap melakukan regresi. Kemudian, peneliti dapat melihat penambahan dari $\mathrm{R}^{2}(R$ Square Change) setiap melakukan analisis regresi dan dapat melihat signifikansi dari penambahan $\mathrm{R}^{2}$ tersebut. Hal ini dapat dilihat pada tabel 6.

\section{Tabel 6}

Proporsi varians kepribadian big five dan coping stress terhadap kecerdasan emosi

\begin{tabular}{|c|c|c|c|c|c|c|c|c|c|}
\hline \multicolumn{10}{|c|}{ Model Summary } \\
\hline \multirow[b]{2}{*}{ Model } & \multirow[b]{2}{*}{$\mathbf{R}$} & \multirow[b]{2}{*}{ R Square } & \multirow[b]{2}{*}{$\begin{array}{c}\text { Adjusted R } \\
\text { Square }\end{array}$} & \multirow[b]{2}{*}{$\begin{array}{l}\text { Std. Error } \\
\text { of the } \\
\text { Estimate }\end{array}$} & \multicolumn{5}{|c|}{ Change Statistics } \\
\hline & & & & & $\begin{array}{l}\text { R Square } \\
\text { Change }\end{array}$ & F Change & df 1 & df 2 & $\begin{array}{c}\text { Sig. F } \\
\text { Change }\end{array}$ \\
\hline 1 & $.383^{\mathrm{a}}$ & .147 & .141 & 8.95446 & .147 & 25.933 & 1 & 151 & .000 \\
\hline 2 & $.529^{\mathrm{b}}$ & .280 & .270 & 8.25364 & .133 & 27.731 & 1 & 150 & .000 \\
\hline 3 & $.588^{\mathrm{c}}$ & .346 & .332 & 7.89333 & .066 & 15.007 & 1 & 149 & .000 \\
\hline 4 & $.588^{\mathrm{d}}$ & .346 & .328 & 7.91938 & .000 & .021 & 1 & 148 & .884 \\
\hline 5 & $.639^{\mathrm{e}}$ & .408 & .388 & 7.55947 & .062 & 15.428 & 1 & 147 & .000 \\
\hline 6 & $.640^{r}$ & .409 & .385 & 7.57695 & .001 & .322 & 1 & 146 & .571 \\
\hline 7 & $.646^{\mathrm{g}}$ & .417 & .389 & 7.55181 & .008 & 1.974 & 1 & 145 & .162 \\
\hline 8 & $.690^{\mathrm{h}}$ & .476 & .447 & 7.18598 & .059 & 16.139 & 1 & 144 & .000 \\
\hline 9 & $.723^{i}$ & .523 & .493 & 6.87671 & .047 & 14.243 & 1 & 143 & .000 \\
\hline 10 & $.743^{b}$ & .551 & .520 & 6.69482 & .028 & 8.876 & 1 & 142 & .003 \\
\hline 11 & $.753^{c}$ & .566 & .533 & 6.60471 & .015 & 4.901 & 1 & 141 & .028 \\
\hline 12 & $.782^{\mathrm{d}}$ & .612 & .579 & 6.27215 & .045 & 16.348 & 1 & 140 & .000 \\
\hline 13 & $.797^{\circ}$ & .635 & .601 & 6.10049 & .024 & 8.990 & 1 & 139 & .003 \\
\hline
\end{tabular}




\section{KESIMPULAN DAN SARAN}

\section{Kesimpulan}

Karakteristik sampel dalam penelitian ini menunjukkan bahwa rentang usia mahasiswa ko-asisten mayoritas berusia 20-21 tahun (79.08\%). Sebagian besar mahasiswa ko-asisten sedang duduk di semester 8 dan semester $10(73.85 \%)$. Sebagian mahasiswa (63.5\%) memiliki skor kecerdasan emosional yang tergolong tinggi. Artinya sebagian mahasiswa ko-asisten dalam sampel penelitian ini memiliki keterampilan untuk mengelola emosi mereka dan tidak terlalu berlarutlarut dalam merasakan emosi yang dirasakan saat mengalami suatu tekanan perasaan yang negatif. Namun demikian, data menunujukkan bahwa ditemukan $36.5 \%$ mahasiswa ko-asisten memiliki kecerdasan emosi yang rendah. Artinya mereka cenderung kurang mampu dalam menglola emosinya, sehingga dibutuhkan perhatian baik dari pihak universitas, rumah sakit, puskesmas untuk mengenali dan mengatasi emosi rendah agar mahasiswa ko-asisten dapat beraktifitas dengan baik.

Kecerdasan emosi memiliki banyak faktor yang mempengaruhi, dalam penelitian ini salah satunya yang diteliti adalah kepribadian big five dan coping stress. Dalam faktor kepribadian big five variabel yang memiliki pengaruh positif yang signifikan terhadap kecerdasan emosional adalah variabel agreeableness. Mahasiswa ko-asisten dalam penelitian ini cenderung memiliki trait agreeableness. Sehingga dapat disimpulkan bahwa sebagian mahasiswa ko-asisten di Jakarta (75.16\%) cenderung menuruti segala aturan dan tuntutan yang diberikan oleh konsulen sehingga mahasiswa ko-asisten mudah beradaptasi dengan tekanan stres nya.

\section{Diskusi}

Selain dalam tuntutannya mahasiswa ko-asisten juga cenderung murah hati dan ramah serta perilaku yang baik yang seharusnya ditanamkan sebagai seorang dokter muda seperti yang dikatakan William (2005). Hasil penelitian ini sejalan dengan penelitian Zee, Thijs, dan Schakel (2002) yang menyatakan bahwa individu yang tinggi dalam trait agreeableness cenderung ramah dan hangat, cenderung memilki rasa hormat terhadap orang lain dan peka terhadap orang lain. Karakteristik ini terkait dengan proses kognitif dan perilaku yang diarahkan pada emosi orang lain.

Karakteristik sampel dalam penelitian ini menunjukkan bahwa rentang usia mahasiswa ko-asisten mayoritas berusia 20-21 tahun (79.08\%). Sebagian besar mahasiswa ko-asisten sedang duduk di semester 8 dan semester 10 (73.85\%). Sebagian mahasiswa (63.5\%) memiliki skor kecerdasan emosional yang tergolong tinggi. Artinya sebagian mahasiswa ko-asisten dalam sampel penelitian ini memiliki keterampilan untuk mengelola emosi mereka dan tidak terlalu berlarutlarut dalam merasakan emosi yang dirasakan saat mengalami suatu tekanan perasaan yang negatif. Namun demikian, data menunujukkan bahwa ditemukan $36.5 \%$ mahasiswa ko-asisten memiliki kecerdasan emosi yang rendah. Artinya mereka cenderung kurang mampu dalam menglola emosinya, sehingga dibutuhkan perhatian baik dari pihak universitas, rumah sakit, puskesmas untuk 
mengenali dan mengatasi emosi rendah agar mahasiswa ko-asisten dapat beraktifitas dengan baik.

Kecerdasan emosi memiliki banyak faktor yang mempengaruhi, dalam penelitian ini salah satunya yang diteliti adalah kepribadian big five dan coping stress. Dalam faktor kepribadian big five variabel yang memiliki pengaruh positif yang signifikan terhadap kecerdasan emosional adalah variabel agreeableness. Mahasiswa ko-asisten dalam penelitian ini cenderung memiliki trait agreeableness. Sehingga dapat disimpulkan bahwa sebagian mahasiswa ko-asisten di Jakarta $\mathbf{( 7 5 . 1 6 \% )}$ cenderung menuruti segala aturan dan tuntutan yang diberikan oleh konsulen sehingga mahasiswa ko-asisten mudah beradaptasi dengan tekanan stres nya. Selain dalam tuntutannya mahasiswa ko-asisten juga cenderung murah hati dan ramah serta perilaku yang baik yang seharusnya ditanamkan sebagai seorang dokter muda seperti yang dikatakan William (2005).

Hasil penelitian ini sejalan dengan penelitian Zee, Thijs, dan Schakel (2002) yang menyatakan bahwa individu yang tinggi dalam trait agreeableness cenderung ramah dan hangat, cenderung memilki rasa hormat terhadap orang lain dan peka terhadap orang lain. Karakteristik ini terkait dengan proses kognitif dan perilaku yang diarahkan pada emosi orang lain.

Variabel kepribadian big five lain yang memiliki pengaruh positif yang signifikan terhadap kecerdasan emosi adalah openness. Artinya semakin tinggi trait openness pada mahasiswa ko-asisten di Jakarta maka akan semakin tinggi kecerdasan emosional yang dimiliki mahasiswa ko-asisten. Sehingga sebagian mahasiswa koas di Jakarta (49.01\%) cenderung kreatif, imajinatif, dan terbuka sehingga mahasiswa ko-asisten yang mengalami stres dapat berpikir secara kreatif dalam menyelesaikan masalahnya. Selain itu mereka juga mudah terbuka dengan orang lain sehingga bisa mencari dukungan kepada orang untuk untuk memberikan suatu saran akan masalah yang ia hadapi. Hal ini sejalan dengan penelitian yang dilakukan oleh Nawi, Redzuan, Hashmi, dan Din (2015) menyatakan bahwa openness dapat menjadi prediktor yang signifikan kecerdasan emosi.

Variabel kepribadian big five lain yang menunjukkan bahwa tidak memiliki pengaruh yang signifikan terhadap kecerdasan emosional ialah extraversion. Akan tetapi mempunyai arah yang positif terhadap kecerdasan emosi. Hal ini menunujukkan bahwa semakin tinggi trait extraversion maka akan semakin tinggi kecerdasan emosi yang dimiliki mahasiswa ko-asisten.

Dalam hasil penelitian ini terdapat hal yang menarik bahwa secara teorinya extraversion seharusnya mempunyai pengaruh terhadap kecerdasan emosi seperti pada penelitian Avsec, Taksic, dan Mohoric (2009) yang menyatakan bahwa adanya pengaruh yang positif antara extraversion dengan kecerdasan emosi. Orang yang mempunyai kepribadian ini cenderung terbuka pada orang lain sehingga mereka mendapatkan saran dan motivasi atau sebaliknya sebagai bentuk praktik keterampilan sosial yang merupakan bagian dari kecerdasan emosi. Hal ini tidak sejalan dengan hasil penelitian yang dilakukan peneliti sehingga peneliti berasumsi bahwa mahasiswa ko-asisten tidak perlu mempunyai trait extraversion tetapi agreeableness yang sangat diperlukan dalam bidang ini dikarenakan orangorang extraversion yang cenderung terbuka dan tidak terlalu menuruti segala 
aturan sehingga mereka akan cenderung cepat merasakan emosinya ketika mereka harus dipaksakan menaaati rangkaian tuntutan aturan yang diberikan oleh dokter konsulen mahasiswa ko-asisten.

Variabel kepribadian big five lain yang menunujukkan tidak memiliki pengaruh terhadap kecerdasan emosi adalah consciencetiousness. Akan tetapi mempunyai arah yang positif terhadap kecerdasan emosi. Sehingga sebagian mahasiswa ko-asisten di Jakarta $(60.78 \%)$ dengan trait ini cenderung pekerja keras, berhati-hati, serta mempunyai ambisi yang meluap-luap sehingga ketika mengalami sesuatu yang diluar dari prediksinya maka akan cenderung susah untuk mengontrol emosinya serta orang yang dengan trait consciencetiousness cenderung tidak bisa terlalu berpikir kreatif dan terbuka. Hal ini sejalan dengan penelitian Zee et al. (2002) yang menyatakan bahwa ketelitian, kehandalan, ketekunan, dan arah tujuan individu yang tinggi dalam sifat ini tidak dapat memonitori, menafsirkan, dan mengatasi suatu emosi.

Pada variabel kepribadian big five lain yang menunujukkan bahwa tidak memiliki pengaruh terhadap kecerdasan emosi adalah neurotiscm. Dalam penelitian ini neurotiscm mempunyai arah yang negatif. Artinya bahwa semakin rendah trait neurotiscm pada mahasiswa ko-asisten maka akan semakin tinggi pula kecerdasan emosi yang dimiliki mahasiswa koas di Jakarta. Sebagian mahasiswa ko-asisten di Jakarta $(46.40 \%)$ berada dalam kategori yang rendah. Hal ini sejalan dengan penelitian yang dilakukan oleh Ghiabi dan Besharat (2011) yang menyatakan bahwa neurotiscm berkorelasi negatif terhadap kecerdasan emosi. Kebanyakan dari mahasiswa ko-asisten memiliki kepribadian yang mudah terbuka pada orang lain, mencari hal yang menyenangkan untuk menghadapi stress nya atau berpikir kreatif bagaimana untuk menyelesaikan suatu masalah. Walaupun hanya ada mahasiswa koas (53.59\%) yang memilki trait neurotiscm sehingga hal itu menjadi penting bagi mahasiswa ko-asisten yang memiliki trait ini untuk melatih dirinya agar mencontoh sifat-sifat kepribadian trait agreeableness dan openness agar dapat meningkatkan kecerdasan emosinya.

Dalam faktor coping stress variabel yang signifikan terhadap kecerdasan emosional dengan arah positif adalah variabel self control. Artinya semakin tinggi self control mahasiswa ko-asisten maka akan semakin tinggi pula kecerdasan emosi yang dimiliki mahasiswa ko-asisten. Dapat disimpulkan bahwa sebagian mahasiswa ko-asisten di Jakarta (41.83\%) memiliki cara coping stress yang baik dengan dapat mengontrol diri emosi dirinya sehingga dapat menempatkan emosinya dengan baik ketika menghadapi masalah sekaligus dapat dengan tenang merawat pasien yang sedang kontrol/rawat jalan. Hal ini sejalan dengan penelitian yang dilakukan oleh Shah dan Thingujam (2008) menyatakan bahwa self control secara positif dan signifikan berkorelasi dengan kecerdasan emosi karena self control keterampilan yang diperlukan didalam kehidupan ketika seseorang tidak memiliki self control mereka mengalami kesulitan mengatur emosi.

Variabel seeking social support yang merupakan variabel dari coping stress memiliki pengaruh positif yang signifikan terhadap kecerdasan emosi. Artinya semakin tinggi seeking social support pada mahasiswa ko-asisten maka akan semakin pula kecerdasan emosi yang dimiliki mahasiswa ko-asisten. Sebagian mahasiswa ko-asisten di Jakarta (45.75\%) memiliki cara coping stress dengan 
mencari dukungan yang didapatkan melalui berbicara dengan orang lain agar mendapatkan saran, dukungan emosi seperti mendapatkan simpati dan pengertian dari orang lain. Hal ini sejalan dengan penelitian Mathews dan Zeidner (2000) dalam Por, Barribal, Fitzpatrick, dan Roberts (2011) menyatakan bahwa orang yang memiliki kecerdasan emosi tinggi mempunyai pola problem focused yang lebih aktif sehingga cenderung mencari seeking social support saat membutuhkannya dan karena itu cenderung tidak megalami reaksi depresi saat menghadapi masalah.

Variabel planful problem solving yang merupakan variabel dari coping stress memiliki pengaruh yang signifikan terhadap kecerdasan emosi dengan arah positif. Artinya bahwa semakin tinggi planful problem solving mahasiswa ko-asisten maka akan semakin tinggi pula kecerdasan emosi yang dimiliki mahasiswa ko-asisten. Sebagian mahasiswa ko-asisten di Jakarta (33.98\%) mempunyai cara coping stress melalui berpikir dan fokus bagaimana masalah akan selesai agar situasi yang dialami berubah menjadi lebih baik. Hal ini sejalan dengan penelitian yang dilakukan oleh Por et al. (2011) yang menyatakan bahwa adanya asosiasi positif yang signifikan antara planful problem solving terhadap kecerdasan emosi.

Variabel positive reappraisal yang merupakan variabel dari coping stress memiliki pengaruh yang signifikan terhadap kecerdasan emosi dengan arah positif. Artinya bahwa semakin tinggi positive reappraisal pada mahasiswa koasisten maka akan semakin tinggi pula kecerdasan emosi yang dimiliki mahasiswa ko-asisten. Sebagian mahasiswa ko-asisten di Jakarta (36.60\%) mempunyai cara coping stress melalui dengan mempunyai pemikiran yang bermakna positif dan menjadikannya sebagai proses pendewasaan pribadi atau lebih mendekatkan diri kepada Tuhan. Hal ini sejalan dengan penelitian Shah et al. (2008) menyatakan bahwa positive reappraisal berkorelasi positif dan signifikan terhadap kecerdasan emosi.

Variabel dari coping stress yang menunujukkan bahwa tidak memiliki pengaruh yang signifikan terhadap kecerdasan emosi adalah variabel distancing. Dalam penelitian ini variabel distancing mempunyai arah negatif. Artinya semakin rendah distancing pada mahasiswa ko-asisten maka akan semakin tinggi kecerdasan emosi yang dimiliki mahasiswa ko-asisten. Dapat diartikan bahwa pada sebagian mahasiswa ko-asisten di Jakarta memiliki cara coping stress ini sangat jarang untuk menciptakan pandangan yang positif ketika menghadapi suatu masalah dan hal ini tidak sejalan dengan penelitian yang dilakukan Shah et al. (2008) yang menyatakan bahwa distancing berpengaruh pada kecerdasan emosional karena dengan berpikir positif agar terlepas dari suatu permasalahan akan membuat tekanan emosional seseorang akan berkurang.

Variabel accepting responsibility yang juga variabel dari coping stress menunjukkan bahwa tidak memiliki pengaruh yang signifikan terhadap kecerdasan emosi adalah variabel accepting responsibility. Akan tetapi mempunyai arah yang positif terhadap kecerdasan emosi. Hal ini sejalan dengan penelitian Por et al. (2011) menyatakan bahwa accepting responsibility mempunyai arah yang positif akan tetapi tidak memiliki pengaruh terhadap kecerdasan emosi. Peneliti berasumsi bahwa pada kalimat di item skala ini tidak cukup peka untuk mengukur kecerdasan emosi karena harus dialami dulu jenis kesalahan dan 
bentuk kesalahannya seperti apa sehingga seseorang baru bertindak untuk bertanggungjawab akan kesalahannya.

Variabel escape avoidance yang juga variabel dari coping stress menunjukkan bahwa tidak memiliki pengaruh yang siginifikan terhadap kecerdasan emosional adalah variabel escape avoindance. Akan tetapi variabel escape avoidance mempunyai arah yang positif terhadap kecerdasan emosi. Dapat disimpulkan bahwa sebagian mahasiswa ko-asisten di Jakarta (44.44\%) memiliki hanya beberapa yang menghadapi masalah dengan coping stress mengharapkan bahwa masalah akan berakhir cepat atau lambat atau berpikir untuk menghindari suatu masalah. Hal ini sejalan dengan penelitian Shah et al. (2008) yang menyatakan bahwa escape avoidance tidak mempunyai hubungan yang signifikan terhadap kecerdasan emosi karena menghindari suatu masalah hanya akan bisa mengatasi stres dalam jangkan pendek.

Variabel confrontive coping yang juga merupakan variabel dari coping stress menunjukkan bahwa tidak memiliki pengaruh yang signifikan terhadap kecerdasan emosi dengan arah yang negatif. Artinya semakin rendah confrontive coping maka akan semakin tinggi kecerdasan emosi yang dimiliki mahasiswa koasisten di Jakarta. Sebagian mahasiswa (49.01\%) memiliki cara coping stress saat mengalami suatu tekanan tidak disalurkan melalui tindakan yang agresif untuk merubah suatu kondisi yang ia alami. Hal ini tidak sejalan dengan penelitian Shah et al. (2008) yang menyatakan bahwa confrontive coping secara positif dan signifikan terhadap kecerdasan emosi karena saat merubah situasi masalah seseorang diharuskan mencoba untuk menghadapi dan mengubah situasi masalah agar tetap wasapada terhadap suatu perubahan dalam emosinya sendiri.

\section{Saran}

Dalam penelitian ini, independent variable secara bersama-sama memberikan sumbangan sebesar $63.5 \%$ terhadap dependent variable (kecerdasan emosi), sedangkan $36.5 \%$ sisanya dijelaskan oleh variabel lain yang tidak diteliti oleh peneliti dalam penelitian ini. Untuk peneliti selanjutnya dapat meneliti variabel lain seperti yang disebutkan dalam faktor-faktor yang mempengaruhi kecerdasan emosi lainnya yang tidak diteliti dalam penelitian ini. Pada alat ukur kecerdasan emosi menunjukkan hasil yang baik sehingga alat ukur ini dapat digunakan pada sampel lain dan menggunakan sampel di luar Jakarta. Untuk penelitian selanjutnya lebih baik menambahkan variabel psikologi eksternal

\section{DAFTAR PUSTAKA}

Abdulghani, H.M., Alkanhal, A.A., Mahmoud, E.S., Ponnamperuma, G.G., Alfaris, E.A. (2011). Stress and its effects on medical students: a crosssectional study at a college of medicine in saudi arabia. International Centre for Diarrhoeal Disease Research, Bangladesh 29(5), 516-522.

Agustina. (2014). Studi mengenai derajat stres dan coping strategy pada koas fakultas kedokteran gigi Universitas Padjadjaran angkatan 2009. Skripsi: Universitas Padjadjaran. Bandung. 
Atta. M., Ather. M., \& Bano. M. (2013). Emotional intelligence and personality traits among university teachers: Relationship and gender diffrences. International Journal of Business and Social Science 4, 253-259.

Avsec. A., Taksic. V., Mohoric. T. (2009). The relationship of trait emotional intelligence with the big five in croatian and slovene university student samples. Horisons of Psychology. 99-110.

Brackett. M. A., River. S. E., \& Salovey. P. (2011). Emotional intelligence: Implications for personal, social, academic, and workplace succes. Social and Personality Psychology Compass. 88-103.

Brannick. M. T., Wahi. M. M., Arce. M., Jhonson. H. A, Nazian. S., \& Goldin. S. B. (2009). Comparison of trait and ability measures of emotional intelligence in medical students. Medical Education. 43, 1062-1068.

Chew. B.H., Zain. A. M., \& Hassan. F. (2013). Emotional intelligence and academic performance in first and final year medical students: A crosssectional study. BMC Medical Education. 13-44.

Compass. B. E., Smith. J. K.C., Saltzman. H., Thomsen. A.H., \& Wadsworth. M. E. (2001). Coping with stress during childhood and adolescence: Problems, progress, and potential in theory and research. American Psychological Association. 1, 87-127.

Dariyo, A. (2008). Psikologi perkembangan dewasa muda. Grasindo: Jakarta. David, R. C., John, D. M., \& Peter, S. (2002). Relation of an ability measuring of emotional intelligence to personality. Journal of Personality Assesment. 79(2), 306-320.

Elizabeth, J. A., Donald, H. S., \& Sarah M. M. (2010). Emotional intelligence, coping and exam-related stress in canadian undergraduate students. Australian Journal of Psychology 1, 42-50.

Feist, Jess \& Feist, Gregory. (2010). Teori kepribadian edisi 7 buku 1. Salemba Humnika: Jakarta.

Feist, Jess \& Feist, Gregory. (2010). Teori kepribadian edisi 7 buku 2. Salemba Humnika: Jakarta.

Folkman. S., Lazarus. R. S., Schetter. C. D., Longis. A. D., \& Rand, J. (1986). Gruen, dynamics of a stressful encounter: Cognitive appraisal, coping, and encounter outcomes. Journal of Personality and Social Psychology 5, 992100.

Fred, C. L. (2011). Emotional intelligence in the workplace: Application to leadership. International Journal of Management, Business, and Administration $14,1$.

García,S., Salguero., \& Fernández, B. (2014). Relationship between emotional intelligence and aggression: a systematic review. Aggression and Violent Behavior 19, 584-591.

Ghiabi. B., Besharat. M.A. (2011). An investigation of the relationship between personality dimensions and emotional intelligence. Procedia Social and Behavioral Sciences 30, 416-420.

Goleman, Daniel. (2015). Kecerdasan emosi mengapa EI lebih penting daripada IQ. Cet. 20. PT Gramedia Pustaka Utama: Jakarta. 
Hall, Lindzey. (1993). Psikologi kepribadian 3 teori-teori sifat dan behavioristik. Penerbit Kanisius: Yogyakarta.

Hardjosastro, Daldiyono. (2006). Menuju seni ilmu kedokteran bagaimana dokter berpikir, bekerja, dan menampilkan Diri. PT Gramedia Pustaka Utama: Jakarta.

Iruloh. B.R., \& Ukaegbu. H.M. (2015). Big five personality traits as predictor of emotional intelligence of secondary school teachers in rivers state of Nigeria. European Journal of Psychology Research 2, 2057-4794.

John, O. P., \& Srivastava, S. (1999). The big five trait taxonomy: history, measurement, and theoretical perspectives. In L. A. Pervin \& O. P. John (Eds.), Handbook of personality: Theory and research (2, 102-138). New York: Guilford Press.

KamusBesar Bahasa Indonesia. Diunduh tanggal 25 agustus 2017 dari https://kbbi.web.id/dokter

Kim. M. R., \& Han. S. J. (2015). A study of emotional intelligence and coping strategies in baccalaurate nursing students. International Journal of BipScience and Bio-Technology .3, 275-282.

Lazarus, Lazarus. (1994). Passion and reason making sense of our emotions. Oxford University Press: New York.

Lazarus, Richard. S \& Folkman, Susan. (1984). Stress appraisal and coping. Springer Publishing Company: New York.

Libbrecht. N., Lievens. F., Carette. B., \& Côté. S. (2013). Emotional intelligence predicts success in medical school. American Psychological Association 1, 64 73.

Lunenburg.F.C. (2011). Emotional intelligence in the workplace application to leadership. International Journal of Management, Business, and Administration $14,1$.

McCrae, Robert R. \& Costa, Paul T. 2003. Personality in adulthood second edition. The Guildford Press: New York.

Nawi. N. H. M., Redzuan. M., Hashmi. S.I., \& Din. A. (2015). Big five personality traits and its effect on emotional intelligence among public school personnel in Malaysia. Southeast Asia Psychology Journal 3, 1-14.

Noorbakhsh. S. N., Besharat. M. A., \& Zarei. J. (2010). Emotional intelligence and coping styles with stress. Procedia Social and Behavioral Sciences 818822 .

Paydab. M. (2009). Factor structure of the Iranian version of ways coping questionnaire. Epidemiology and Public Health Sciences. 1-33.

Pervin, Cervone, \& John. (2004). Psikologi kepribadian: Teori dan penelitian edisi 9. Kencana Prenada Media Group: Jakarta.

Por. J., Barriball. L, Fitzpatrick. J., \& Roberts, J. (2011). Emotional intelligence: its relationship to stress, coping, well-being and professional performance in nursing students. Nurse Education Today 31, 855-860.

Purwandito, A., Soetedjo, Gunawan, Sintak, Budiningsih, Yuli., Prawiroharjo, P., Firmansyah., \& Ade. (2012). Kode Etik Indonesia. Pengurus Besar Ikatan Dokter Indonesia. 
Salovey, Peter., Mayer, \& John D. Emotional intelligence. (1997). Baywood Publishing Co., Inc.

Salovey. P., Stroud. L. R., Woolery. A., \& Epel. E. S. (2002). Perceived emotional intelligence, stress reactivity, and symptom reports: Further explorations using the trait meta-mood scale. Psychology and Health. 5, 611-627.

Shah. M., \& Thingujam. N. S. (2008). Perceived emotional intelligence and ways of coping among students. Journal of the Indian Academy of Applied Psychology 1, 83-91.

Shelley. T. E., dkk. (2009). Psikologi sosial edisi dua belas. Kencana Prenada Media Group: Jakarta.

Sindhuja, C.V., Shrivastava, J. K., Gambhir, S., \& Chaturvedula, S. (2013). A study on trait emotional intelligence and personality type of Indian military pilots: a preliminary study. Ind J Aerospace Med 57(1), 1-12.

Suldo. S. M., Shaunessy. E., \& Hadesty. R. (2008). Relationships among stress, coping, and mental health in high achieving high school students. Psychology in the Schools 45(4), 273-290.

Todres. M., Tsimtsiou. Z., Stephenson. A., \& Jones. R. (2010). The emotional intelligence of medical students: An exploratory cross-sectional study. Medical Teacher 32, 42-48.

Umar, J. (2013). Confirmatory factor analysis. Bahan ajar perkuliahan. Fakultas Psikologi UIN Jakarta.

Wade, Carol \& Tavris, Carol. 2007. Psikologi edisi 9. Penerbit Erlangga: Jakarta.

Williams, J. R. (2005). Panduan etika medis. Pusat Studi Kedokteran Islam Fakultas Kedokteran Muhammadiyah Yogyakarta.

Yahaya, A., Ee. N.S., Bachok. J. D. J., Yahaya. N., Bon. A. T., \& Ismail. S. (2011). The relationship of dimensions of emotional intelligence and academic performance in secondary school students. Elixir Psychology 41, 5821-5826.

Zee. K. V. D., Thijs. M., \& Schakel. L. (2002). The relationship of emotional intelligence with academic intelligence and the big five. European Journal of Personality 16, 103-125.

Zheng. L., Goldberg. L. R., Zheng. Y., Zhao. Y., Tang. Y., \& Liu. L. (2008). Reliability and concurrent validation of the IPIP big five factor markers in China: Consistencies in factor structure between internet obtained heterosexual and homosexual samples. Personality and Individual Diffrences 45, 649-654. 